\title{
ANAESTHETIC MANAGEMENT OF A CASE OF PHAEOCHROMOCYTOMA
}

\author{
C. J. KIIDUFF, M.D. (\$ASK.), M.B., B.CH., F.A.C.A. ${ }^{*}$
}

THIS IS A REPORT on the management of an adult patient for the removal of a phaeochromocytoma. It is of special interest as the patient was anaesthetized twice with the tumour present. The anaesthetic management was essentially the same on each occasion but the method of blood pressure control was different for each operation.

\section{CASE Report}

The patient was a 49-year-old female, weighing 96 pounds and 60 inches in height. She was admitted to hospital with a six-year history of hypertension, paroxysmal headache, profuse sweating, nausea, and anxiety.

On admission the blood pressure was $170 / 110 \mathrm{~mm}$. $\mathrm{Hg}$, but it rose to $260 / 150$ $\mathrm{mm}$. Hg. during an attack. An intravenous injection of $5 \mathrm{mg}$. of phentolamine (Rogitine ${ }^{\circledR}$ ) given during an attack resulted in a prompt drop in blood pressure. Chest X-ray showed a moderate degree of left ventricular enlargement of the heart; the intravenous pyelogram was normal. Retroperitoneal gas insufflation suggested a left adrenal tumour. The ECG showed left ventricular hypertrophy with ischaemia and left heart strain. Urinalysis, glucose tolerance test, blood urea, and serum electrolytes were all normal. B.M.R. +21 and +29 ; E.S.R. 91 $\mathrm{mm}$. in one hour.

The diagnosis of phaeochromocytoma was made on the basis of the clinical history, two positive phentolamine tests, and the elevated urinary excretion of 3-methoxy, 4-hydroxy mandelic acid and catecholamines. The retroperitoneal gas study seemed to localize the tumour in the left adrenal gland.

\section{ANAESTHETIC MANAGEMENT}

In order to prevent undue fluctuations of blood pressure during operation it was decided to prepare the patient with intravenous phenoxybenzamine hydrochloride (Dibenzyline hydrochloride ${ }^{\circledR}$ ). This drug is highly effective in the specific blockade of excitory responses caused by adrenergic stimuli. Consequently, the patient was given $1 \mathrm{mg}$. of phenoxybenzamine hydrochloride per kilogram mc body weight intravenously on the day before operation. The blood pressure for 2 hours before administration in the prone position had been $212 / 130 \mathrm{~mm}$. $\mathrm{Hg}$ and the pulse rate $84 /$ minute. Administration of the drug was started with the patient's head and shoulders elevated $10^{\circ}$ as this made her more comfortable. After 90 minutes the blood pressure was $80 / 60 \mathrm{~mm}$. $\mathrm{Hg}$, at which time $25 \mathrm{mg}$. of phenoxybenzamine had been given. The intravenous infusion was temporarily discontinued for 15 minutes, and the blood pressure

*Department of Anaesthesia, University Hospital, Saskatoon, Sask. 


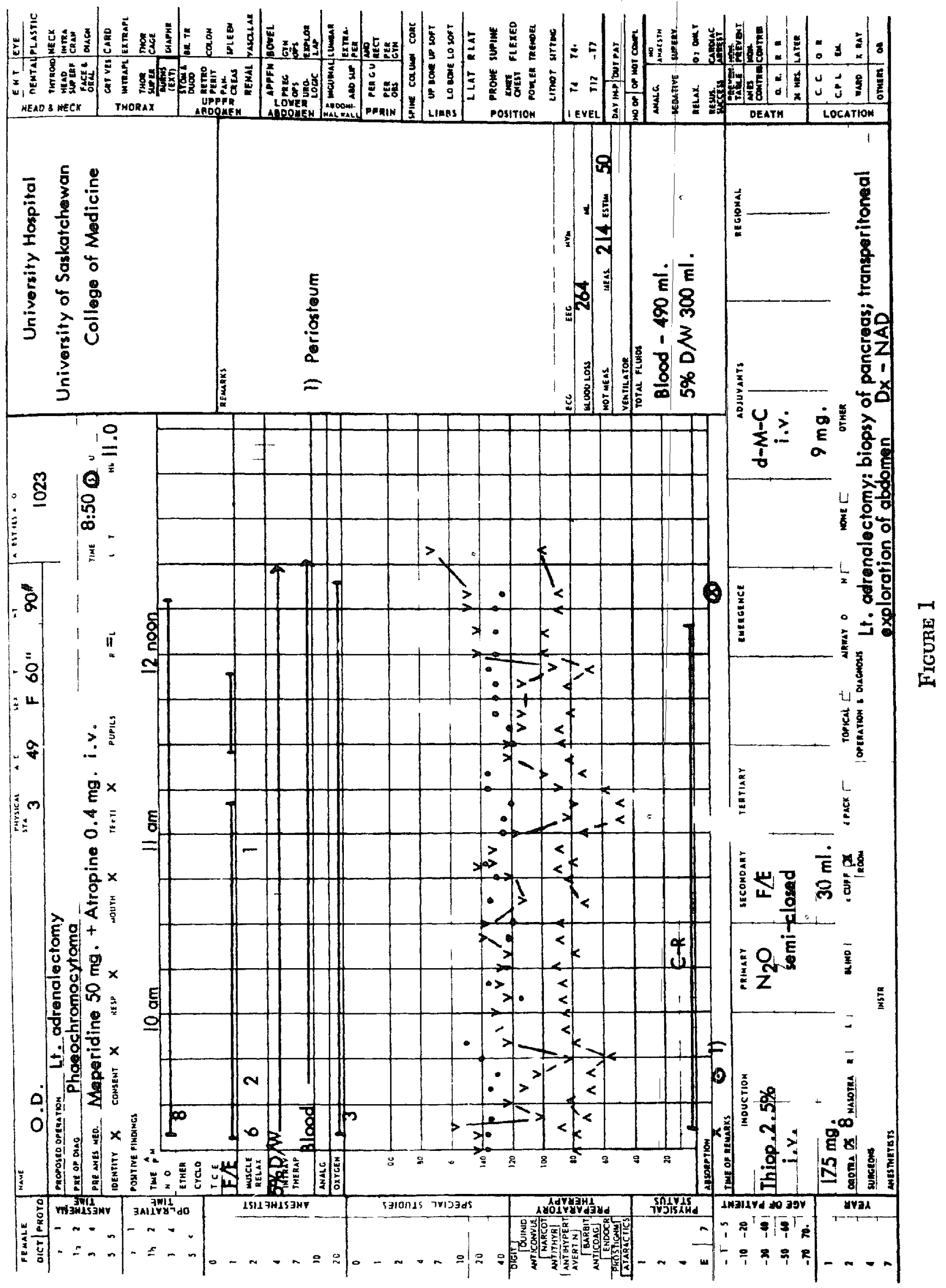


rose to $120 / 80 \mathrm{~mm}$. $\mathrm{Hg}$ following bandaging of the legs and placing of the patient flat. The remainder of the drug was then administered over the next 15 minutes. This caused no further change in blood pressure, which remained stable during the following night. The patient was given $200 \mathrm{mg}$. secobarbital by mouth for night sedation. The following morning the previous dose of phenoxybenzamine was given 90 minutes before induction of anaesthesia, again without any further change in blood pressure.

Endotracheal anaesthesia was induced with thiopental and anaesthesia was maintained with nitrous oxide - oxygen and fluothane-ether azeotrope, with dimethyl-tubocurare for added relaxation. Respiration was controlled throughout the operation. The patient was placed in the acutely flexed kidney position for left lumbar exploration. The blood pressure dropped momentarily when the periosteum was being stripped from the left 12th rib and again uring the blind exploration of the abdomen through the lumbar incision (Fig. 1).

A tumour was not found during this operation but the left adrenal gland was removed for microscopic examination. After 3 hours of anaesthesia the blood pressure was $160 / 100 \mathrm{~mm} . \mathrm{Hg}$ and it reached $200 / 100 \mathrm{~mm}$. $\mathrm{Hg}$ within 10 minutes of the end. Thirty-eight minutes after anaesthesia was discontinued (that was 4 hours after administration of phenoxybenzamine), the patient was awake and the blood pressure was $200 / 110 \mathrm{~mm}$. Hg. Two hours later $2 \mathrm{mg}$. of phentolamine was given intravenously and this was effective in lowering the blood pressure. The patient made a very satisfactory recovery from operation and anaesthesia.

Twelve days post-operatively the patient had another attack heralded by sudden frontal headache, turning hot all over, palpitation, and profuse sweating. The blood pressure rose to $280 / 150 \mathrm{~mm}$. $\mathrm{Hg}$. Phentolamine tests were performed in the afternoon and were again markedly positive. The histamine test was also repeated. There was a marked rise in blood pressure following this test with a typical histamine flush, severe headache, and nausea. This was again highly suggestive of the presence of a phaeochromocytoma. Urine was collected for catecholamine studies and the results of these determinations are listed in Table I.

TABLE I

\begin{tabular}{ccc}
\hline \hline & $\begin{array}{c}\text { Norepinephrine, } \\
\text { mg./24 hr. }\end{array}$ & $\begin{array}{c}\text { Epinephrine, } \\
\text { mg./24 hr. }\end{array}$ \\
\hline Days before operation & 232 & 130 \\
13 & 271 & 199 \\
12 & 298 & 203 \\
11 & 714 & $145^{*}$ \\
10 & & 41 \\
Days after operation & 120 & 30 \\
2 & 86 & 24 \\
3 & 57 & $3-31$ \\
4 & $25-130$ &
\end{tabular}

*Patient had a hypertensive attack on this day. 


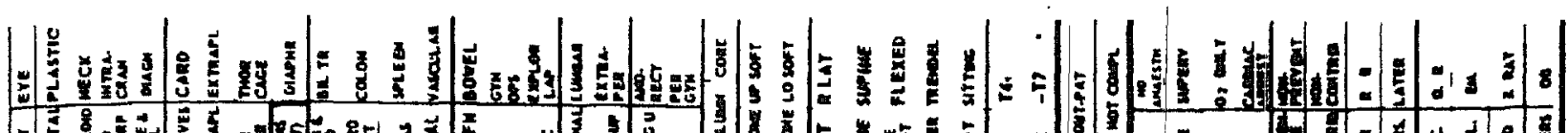

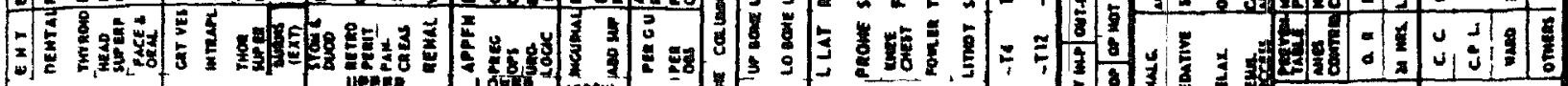

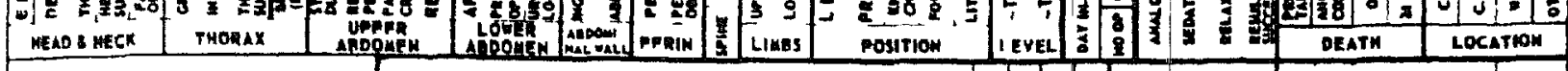

$\frac{\sqrt[m]{1 / 2}}{\frac{1}{12}}$

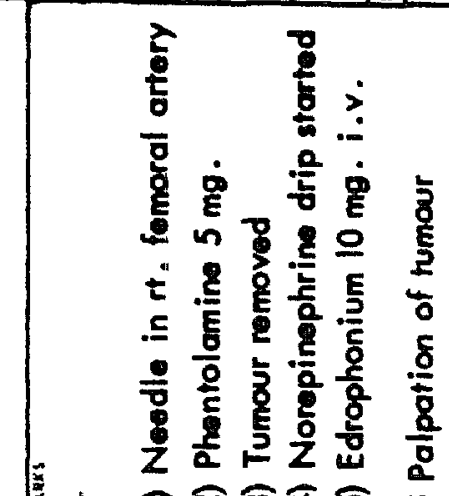

.

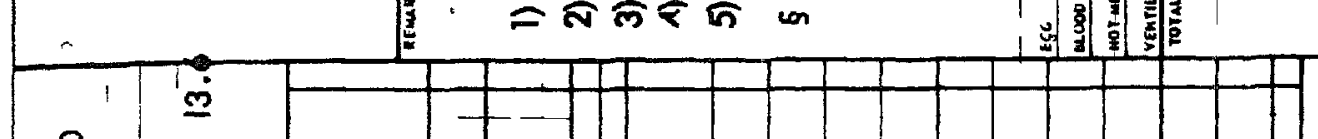

ind

$: \bar{a}$

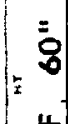

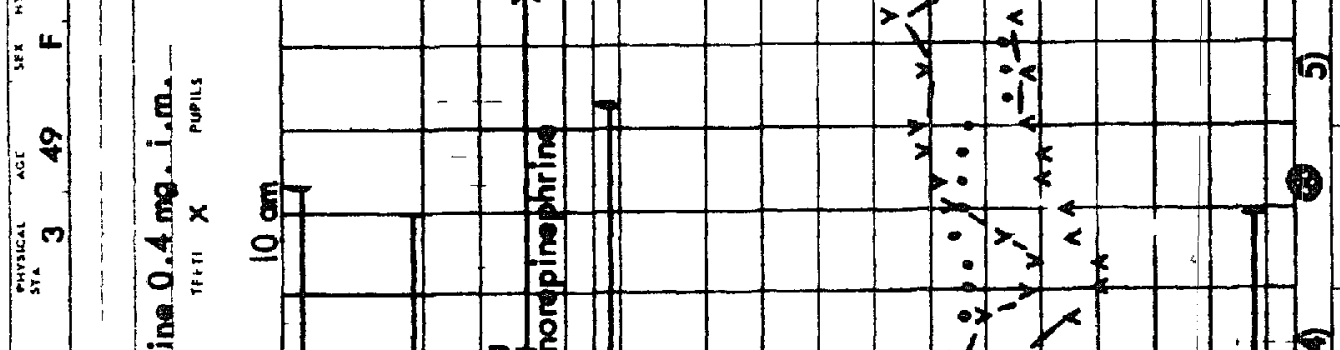



量:

Q)

$1+=$

$\frac{g}{2} x$

量 $\times 1$

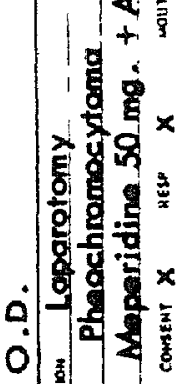

*

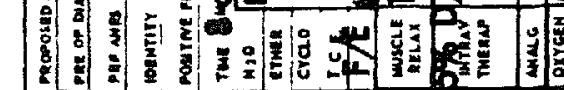

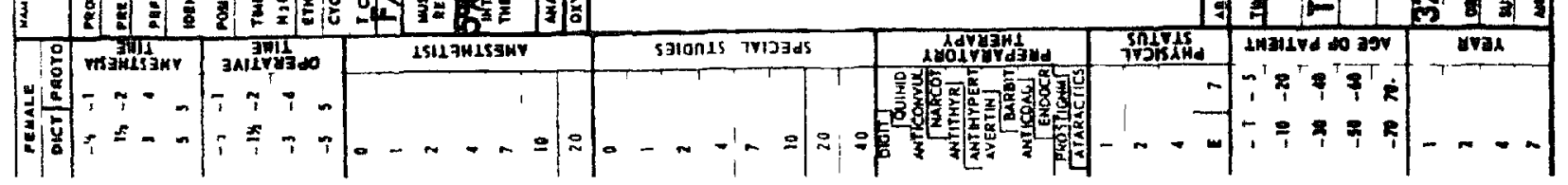


Twenty-two days after the first operation the patient's abdomen was reexplored, this time through a right paramedium incision without the use of phenoxybenzamine. It was felt that omission of that drug might facilitate localization of the tumour by the resultant blood pressure changes. It was decided to control any hypertension episodes with intravenous phentolamine, and hypotension with norepinephrine. One further difference between this and the previous operation was that the patient had been on hydrocortisone preoperatively because of the left adrenalectomy performed at the previous operation. Blood pressure during this operation was measured directly from the right femoral artery, EKG was also monitored continuously, General anaesthesia was conducted in the same fashion as during the first anaesthesia.

Before induction of anaesthesia, the blood pressure was $220 / 120 \mathrm{~mm}$. $\mathrm{Hg}$, and it fell to $125 / 90 \mathrm{~mm}$. Hg after induction and remained so until the peritoneum was opened (Fig. 2). The tumour was located and as it was being manipulated, the blood pressure rose to $270 / 120 \mathrm{~mm}$. Hg with a bout of cardiac arrhythmias. Manipulation was stopped, and blood pressure and arrhythmias were controlled with $5 \mathrm{mg}$. of phentolamine given intravenously. This dose was repeated on another five occasions to icontrol hypertension; cardiac arrhythmias were infrequent after the first occasion.

After removal of the tumour the blood pressure immediately fell from $270 / 130 \mathrm{~mm}$. $\mathrm{Hg}$ to $110 / 90 \mathrm{~mm}$. $\mathrm{Hg}$ and then to $80 / 60 \mathrm{~mm}$. $\mathrm{Hg}$ over the next 15 minutes. Norepinephrine administration was delayed for 5 minutes after removal of the tumour to test for the possible presence of a second tumour. Twenty minutes after norepinephrine administration had been started the blood pressure started to rise and it reached $120 / 80 \mathrm{~mm}$. $\mathrm{Hg}$ in 10 minutes, at which time the operation was completed. The patient was kept on the operating table for 45 minutes to allow vital signs to stabilize. One hour later she was fully awake in the recovery room.

The blood pressure maintained itself at approximately $120 / 80 \mathrm{~mm}$. $\mathrm{Hg}$ and norepinephrine was discontinued after 4 hours 45 minutes without any change in blood pressure. The total dose of norepinephrine used was $0.04 \mathrm{mg}$.

\section{Discussion}

This was an interesting case as it afforded the rare opportunity to use two different techniques to control blood pressure in the same patient within a short period of time. It also demonstrated that manipulation of the tumour, although not recognized as such at the time of the first operation, did not alter blood pressure or produce cardiac irregularities under phenoxybenzamine block. The unblocked patient, during the second operation, demonstrated the hazards of the older phentolamine/norepinephrine method.

Cardiac arrhythmias are not uncommon during anaesthesia and their incidence is increased by a high level of catecholamines. The circulating epinephrine and norepinephrine pose serious problems in the anaesthetic management and account for the high operative mortality rate. ${ }^{1}$ The hypertensive crises can give rise to acute pulmonary oedema or cerebral haemorrhage. Prolonged use of 
norepinephrine intravenously can lead to local damage of the limb and produce a ganglionic-type blockade which makes the patient even more dependent upon norepinephrine.

The use of phenoxybenzamine with an exploratory laparotomy would appear to make the anaesthesia and operation safer for the patient. However, it makes the localization of a small tumour and of secondary tumours more difficult. Barbeau et al. ${ }^{2}$ found that 45 cases of bilateral tumours had been described up to 1957, making an incidence of 7 per cent. The incidence of multiple tumour is, however, more common than this, for phaeochromocytomata also occur in other tissues derived from the neural crest, such as the organs of Zuckerkandl and the sympathetic ganglia. But their incidence is more likely to be smaller than that of cardiac arrhythmias, hypertension, and hypotension in the unblocked patient. Small tumours are more likely to produce a lower level of catecholamines than large ones and make the use of either technique safer. It is suggested that the size of a tumour is, to some extent, determined by the ability of its cells to methylate norepinephrine and to store epinephrine. ${ }^{3}$

\section{ACKNOWLEDGMENT}

I should like to thank Professor M. Nickerson, M.D.(Utah), A.B.(Linfield), SCM.(Brown), PH.D.(Johns Hopkins), Professor of Pharmacology, University of Manitoba, Winnipeg, Manitoba, for his advice on the use of phenoxybenzamine.

\section{REFERENCES}

1. Apgar, VIrginta, \& Papper, E. M. Phaeochromocytoma Anaesthetic Management during Surgical Treatment. A.M.A. Arch. Surg. 62: 634 (1951).

2. Barbeau, A.; Marc Aurele, J.; Le Boeuf, G.; Broutllet, J.; Cartier, P.; Vitye, B.; Mignault, G.; \& Genest, J. Le pheochromocytome bilateral. Un. med. Can. 87: 165 (1958).

3. Sjoerdsma, A.; Leeper, L. C.; Terry, L. L.; \& Udenfriend, S. Studies on the Biogenesis and Metabolism of Nor-epinephrine in Patients with Pheochromocytoma. J. Clin. Investigation, 38: 31 (1950). 